\title{
Cloud Computing Uses for E-Government in the Middle East Region Opportunities and Challenges
}

\author{
Naser N. ALMutairi ${ }^{1} \&$ Shebaib Fahad Thuwaini ${ }^{1}$ \\ ${ }^{1}$ Public Authority of Applied Education and Training, College of Business, Management Department, Kuwait \\ Correspondence: Naser Almutairi, Public Authority of Applied Education and Training, College of Business, \\ Management Department, Kuwait. Tel: 965-9666-6514. E-mail: kww666@yahoo.com
}

Received: August 25, 2014

Accepted: February 12, 2015

Online Published: March 27, 2015

doi:10.5539/ijbm.v10n4p60

URL: http://dx.doi.org/10.5539/ijbm.v10n4p60

\begin{abstract}
This research paper seeks to investigate the cloud computing opportunities, challenges, and service models for e-government in the Middle East. For more than ten years now, the Internet alongside its correlated Web 2.0 applications have become instrumental to both businesses and consumers as it improves the day to day processes, communication and flow of information both within and with government institutions. A number of e-government services being utilized globally offer societies with comparatively sophisticated applications and services. To this end, government can even improve their web services on offer with the institution of a fiber-based broadband network. As it will be discussed herein, many governments in Middle East have identified the significance of IT in improving and sustaining their economy. The paper will introduce the topic and an overview of cloud computing in the Middle East, followed by the methodology. The literature review part will investigate the many researches done by other authors on the same topic. The facts gathered will then be analyzed and comparison done between Europe and Middle East with regards to the use of cloud computing for e-government before the conclusion and recommendation offered.
\end{abstract}

Keywords: cloud computing, technology, Middle East, government, software, malware, cyber

\section{Introduction}

As it will be discussed in this research paper, many governments in the Middle East have realized the significance of IT in improving and sustaining their economies as well as having an effective infrastructure where communication is fast so as to achieve such a goal. Consequently, numerous ICT initiative have been undertaken, specifically within governments. Many of these countries are utilizing the advantage of the absence of issues of legacy to make use of the latest technology and its infrastructure. Investment in IT, especially in GCC countries, including the likes of Saudi Arabia, UAE, and Qatar have been tremendous. These governments are keen enough to take their departments and services online as they seek to improve their infrastructure and services to the people. For instance, the UAE has embarked on a number of e-applications that will fast track government activities. As Ghaffari (2010) acknowledges in his research, cloud computing is the answer to the increased power consumption and cost of data storage.

In view of this, cloud computing is one of the hottest research topics in universities and research centers in relation to information technology (Hashemi et al., 2012). Before going into further details, what is cloud computing really? National Institute of Standards and Technology defines cloud computing as the computer networking that allows data storage and the delivery of information technology in a central place with online access via computer services (Hashemi, 2012; Takabi et al., 2010). A very common and simple definition of cloud computing is a scalable and capable instrument that is technologically enabled and is easily available on the internet depending on the users' demand (Hashemi, 2012; Takabi et al., 2010; Gidado et al., 2011; Ghazali et al., 2011; Jamil et al., 2011). In cloud computing, all the computers are configured in such a way that all the applications work collectively as if they are on the same system. Cloud computing has come to existence due to the evolution and the development of technology (Keizer, 2009). Shared resources and the congregate infrastructure is the foundation of cloud computing. The major components of cloud computing includes, the network, a front end and a back end platform and a cloud based delivery, which form its architecture (Krissi, 2008). 


\section{Literature Review}

\subsection{Characteristics and Components of Cloud Computing}

A study done by Ghazali et al. (2011) notes that, it is important to comprehend the significance of the cloud's components and features, the use of the developed models and how to use cloud computing services so as to know and accept cloud computing. According to the National Institute of Standards and technology, cloud computing has five distinctive characteristics; resource pooling, wide network access, measured service, on demand self-service, elasticity (Hashemi, 2012; Takabi et al., 2010; Gidado et al., 2011; Ghazali et al., 2011; Jamil et al., 2011). In resource pooling, the main computer resources are gathered in a centralized place so as to serve several users through a model that is multi-tenant and it possess different virtual and physical resources which are assigned as well as reassigned in line with the customers' demands.

Hashemi (2012) and Takabi et al. (2010) have defined four types of clouds. Also in his Master's thesis, Sachdeva (2011) depicts that there are public and private clouds; public cloud is for public use, specifically to those who have access to web service, resources and application. On the other hand, private cloud as cloud applications that can only be accessed by the individuals in an organization while barring the those out of the organization from accessing them. According to Winkler (2011), community cloud is prepared and provides some common resources and application made available. Hybrid cloud combines the private, public or community clouds and it uses external and internal cloud service providers (Khawaja et al., 2012). Also in a study by Tong et al. (2012), he notes that cloud computing has a wide network access where the capabilities and applications are made available in the whole network and is easily accessed through thick and thin platforms such as the laptops, mobile phones, tablets and workstations. Computer capabilities and applications are easily released and provided according to the user demand which is available to the user in unlimited amount at any given time (Ristenpart et al., 2009).

\subsection{Components of Cloud Computing}

According to research by Ferrer (2009), cloud computing comprises of two main components: the front end and the back end, which get to be connected by the Internet. The back end refers to the cloud itself and it provides the computers' data storage, which develops the cloud's services, servers and applications. The front end refers to the medium through which the user accesses the system and it comprises of the various applications that users use to access the clouds and a computer network. Hashemi (2012) and Takabi et al. (2010) present cloud services in three models: infrastructure as service (IaaS), platform as service (PaaS), and software as service (SaaS). The cloud has a virtual machine monitor (VMM) that allows simultaneous of the cloud's applications. These layers are the infrastructure layer, platform layer and the application layer. The infrastructure layer is the base of the cloud which comprises of the network devices, the storage facilities and the servers. While using Infrastructure as a Service (IaaS), the user has no control over the basic infrastructure other than the storage, operating systems, some applications and network components.

The platform layer provides the application infrastructure. As Sachdeva (2011) notes, through the Platform as a Service (PaaS), a user can access the operating systems and other services. PaaS provides the user with a medium to deploy computer applications to the cloud by use of programming thus the user has control over the deploying applications alone. The application layer is mostly seen as the cloud. All the applications go through the application layer, which is provided by demand to the users (Hashemi, 2012; Takabi et al., 2010; Gidado et al., 2011; Ghazali et al., 2011; Jamil et al., 2011; Khawaja et al., 2012; Winkler, 2011; Sachdeva, 2011). An example of Software as a Service (SaaS) is Google Pack. Figure 1 shows the components of the cloud. 


\begin{tabular}{|l|l|}
\multicolumn{2}{|l}{} \\
\multicolumn{2}{|l|}{ Cloud clients (Web browsers, mobile apps, thin clients) } \\
\hline Application & $\begin{array}{l}\text { SaaS } \\
\text { CRM, email, games, virtual desktop , communication, games }\end{array}$ \\
\hline Platform & $\begin{array}{l}\text { PaaS } \\
\text { execution runtime, database, web server, developmental tools }\end{array}$ \\
\hline Infrastructure & $\begin{array}{l}\text { IaaS } \\
\text { Virtual machines, servers ,storage, network, load balancers }\end{array}$ \\
\hline
\end{tabular}

\subsection{Challenges of Cloud Computing}

In their research, Shravan et al. (2012) acknowledge that, for an e-government to be effective, it has to be reliable, easy to maintain and economical, although Middle East countries are among the richest counties in the world. Cloud has benefited millions of people because it has helped in closing the communication gaps among the residents of remote areas. Nonetheless, e-government in the Middle East has come under economic, political and social challenges (Parihar, 2011). Cloud computing challenges limit the governments' effort for effective use of e-government. According to Gopala et al. (2009) and Sheridan (2006), technical challenges such as system integration, management policies, data scaling, disaster recovery, auditing, and replication are the most crucial, but with cloud computing, there are tools and technology that simplifies and eases the challenges

Software as a Service (SaaS) has proved to be difficult in its implementation and usage. A user with a computational need might be unable to find an appropriate application for his demand in the application layer, in which case the user has to buy and install that particular software physically in the computers (Voith et al., 2010). In cases where the venders allow the users to move to other new vendors, the user is charged a very high fee. It is difficult for Softwares as a Service to obtain cheap hardware and open source applications. The attacks on shared tenancy have increased by $24 \%$ in the past half a decade. Data from different users are stored in one particular computer although it is hosted on different virtual machines. Virtual machine should run concurrently although with no information of what other virtual machine is running.

Recently however, some researchers from Massachusetts Institute of Technology found out that one virtual machine can be used to copy another virtual machine's information by mapping the internal infrastructure of the cloud (Ristenpart et al., 2009). Mapping the internal infrastructure of the cloud causes a data breach. From the findings of the research, the world is made aware of the vulnerability of the cloud servers and how it could be exploited by criminals. Cloud attackers are targeting the operations of the cloud users as they try to get unauthorized access to information and data (Cloud Security Alliance, 2010). Various types of malwares that cloud attackers are using to gain access to data. According to Keizer (2009), the attackers use the malware to infect the servers in the cloud. After accessing unauthorized data, the malware hides the files and operating systems from the users' security programs and antivirus. The malware gives the attacker complete access to a users' data and they can manipulate it as if the owner is the one doing it.

Botnet is a malware that maximizes on the vulnerability of the system. It allows opening of backdoors by the hackers without the authorized users' knowledge. Most cyber criminals use botnet to abuse the cloud through flooding the server with bogus messages, denying the authorized user access, cyber bullying or tying the system up (Ferrer, 2009). Recently, it is rumored that the cloud could be the attackers' launching pad where they can launch brute force. A brute force is a strategy that can break encrypted data by trying password combinations of decryption keys. When a user hosts his data with the cloud service providers, he entrusts confidential and a very large amount of information to the providers. The risk of hosting such data to the cloud service providers is that the rogue service providers mine the same data and resell it to the users' who can be an individual, an organization or a country, enemies of competition resulting to a leakage of data (Proofpoint, 2009). One an enemy gets a country's' data, that country is vulnerable to terrorist attacks.

\subsection{Future Trends in Cloud Computing}

Most governments in the Middle East, especially Kuwait, Qatar, Cyprus, United Arab Emirates and Jordan, are 
doing their best to promote cloud services to aid in daily activities that are in direct interaction with it citizens (Layne, 2001). As Tamizi et al. (2003) and Shravan et al. (2012) acknowledge, e-government is a cloud service that provides services to the citizens such as access to information which gives them an opportunity to participate in the economic and social development of their country. Tamizi et al. (2003) and Parihar et al. (2011) define e-government as the use of ICT to improve the effectiveness and efficiency, comparability of financial information and transparency within and between the government and its citizens, subordinate organizations and private sector. According to research by Sheridan (2006) and Gopala et al. (2009), e-government provides the government with services such as digitization of tax information, records, collection and dissemination of data, election process and its management.

With the continuing evolution of technology, it will reach a time when cloud computing will be so overwhelming that it will have to retain just its computing name although it will be evolving as an approach to technology. The cloud service providers have not yet found the perfect fit-for-fit and function for the whole demand market. Because of this, there have been several occasion of failed cloud service of the lack of the software until installed physically but in the near future technology will have developed to a point where all this applications will be possible by just a click of a button (Guo et al., 2012). In time, centralized data will be of big advantage to the users where many will gain the expertise to establishing databases in the cloud that cloud dispenses information easily available such as wide range of clinical data that will ensure better health care. Devices such as mobile phones, in their smaller and thinner size, will take over computers where they will contain all the computing capabilities and application. With such mobile phones, the use of clouds will be closer and easily accessible than ever (Tong et al., 2012).

\subsection{The Significance of Cloud Computing to Governance in the Middle East}

The increased desire of the Middle East region to increase their 24 hour all week services, communication and report issues has strongly motivated many governments to invest in cloud computing. An example of the case in Karnataka where centuries-old records for land registry are being digitalized (Weinman, 2012). The significance of the above process is to eliminate corruption and inefficiencies by showing taxes owed and proof of ownership. In fostering good service provision to Middle East citizens, the government of Karnataka uses the Bhoomi project, meaning land, to make transparent records for better auditing by the local government and easy access to information needed for effective service provision to residents. The eSeva is another initiative in Telangana state that allows, direct payment of telephone bills, utility and municipality taxes by citizens from the state's website (Kling, n.d.).

\section{Type of Applications Used by the Governments}

\subsection{Government to Government}

This application involves the sharing of electronic information/data between organizations, government agencies and departments, the aim being to improve communication, data sharing and data access. The Middle East just as any other region within federal governments is driven by factors amongst, funding and budgeting of its citizens and the Open Government Directive legislation. Through systems and information sharing, the Middle East governments are able to reduce IT costs, streamlining procedures at government offices, citizens are also able to access information using internet. Qualifications for funding and project grants are also fastened.

\subsection{Government to Business}

It refers to a non-commercial online interaction between commercial business sectors and the central and local government rather than private individuals. The aim is to for the government to provide advice and business information on governments best e-practices.

\subsection{Government to Citizens}

This refers to the communication link between the private residents or individuals and the government. It often accentuates to the communication-taking place communication and information technologies (ICTs) but may also involve media campaigns and direct mails. The cloud computing application can take place at the local level, state or federal level.

\subsection{Government to Employee}

Similarly, this is an on-line interaction between the government and its employees. The application is an instantaneous tool for communication that helps in educating employees on government plans, promoting knowledge and bringing them together. It also provides the possibility of employees accessing information in regard to benefits policies, compensation learning civil right laws and training opportunities. Software for 
maintaining records and personal information of employees is also included.

\section{Methodology}

As a methodology, this research paper seeks to gather information about cloud computing for e-government in the Middle East mostly from previous studies, journals, and books on the same topic. I apply theories used by Richard, et al. (2009), Probst and Raisch (2005) and Megicks (2001) in their works where they note that government have embarked on e-government programs and services to enable exchange of information and access to services such as land management, tax, e-health, electronic payment, e-procurement, and business registration. Their theoretical framework is significant because the ICT sector in the Middle East region has been on the rise significantly due to high rates of subscriptions, mobile data demand, and competition, thus the use of cloud computing in e-government is significant. Using secondary research will enable this paper to gather a wide variety of information from this topic. The advantage being that it is possible to analyze different researches and thus come up with a viable conclusion and effective recommendations.

\section{Analysis}

\subsection{Ways in Which the Middle East has Used Cloud Computing in E-Governance}

Major commitments have been made by the Middle East government to reform and modernize government with the aim of broadening access to services provided by the government, achieve greater efficiency and improve service levels. The ultimate aim of e-governance is to centralize, seamlessly make government services cohesive to its end-users.

\subsection{Media}

Middle East media companies are increasingly using cloud computing to boost revenues and as a means of storing valuable on-line business information. The valuable technology allow media companies to share information at any time as long as they have internet access. Investment of money in cloud-based businesses is equally on the rise within the region. The traditional computer sharing of data has since faced off and the result has seen media companies save money on maintenance and equipment costs. Purchase of media software and hardware is also done electronically in most media houses.

A case of Dubai where media technology experts hold seminars to plan and discuss ways of strengthening e-broadcasting has generated great profit to their companies. Data has been moved to more virtual environments that has helped address various concerns on safety. Proper backing up of business information for easy recovery during any disaster has proved efficient. The remarkable progress has been realized by various media companies such as Etisalat, which is based at Abu Dhabi, the aforesaid signed a cloud agreement with Huawei to strengthen their profit margin and customer base. The two companies are planning a partnership of providing more innovative technologies that also includes computing services. Amazon.com has also opened an annual start-up challenges that allows businesses emerging from the Middle East to compete for cash that tunes to 100,000 US dollars. The latter is meant for credit and cash to be used for cloud computing services. One condition of eligibility for start-ups is to describe their business plans and demonstrate ways in which cloud computing services are factoring in their eligibility.

\subsection{Disaster Recovery and Management}

The leading technology firm, Edarat Group in the Middle East and the Gulf region has recently partnered with Evault, their main aim is to support the capability of companies in Saudi Arabia and those in United Arab Emirates protect valuable data. The mechanism involves use of advanced project management techniques hence managing over 200 projects every year. The companies provide its regional users various Cloud Disaster Recovery services that are encrypted as Evault. The data recovery aims at virtual, secure cloud based environment. Both the private and public sector, has over the past few years, offered a strong corporative effort expanding the quantity of quality online services. The result has since encouraged various ICT communities to focus on diversifying and modernizing their local economies within their corresponding infrastructure.

The assessment of international players and regional market led to selection of EVault by Edarat due to its affirmed leadership in delivering disaster recovery services. Replication of the data managed to a top-tier network was very important to Edarat whereas, the Edarat customers were more concerned on the ability of EVault to provide them with en-to end encryption that would ensure their data always remained private and can comply with various regulatory requirements. The forester wave supported the decision, later named as Disaster-Recovery aimed at Service Provision, Q1 2014. EVault CDR has supported for the first time in the United Arab Emirates and Saudi Arabia (Marks \& Lozano, 2010). The regional dispersion of state-or-art infrastructure in Qatar, UAE, Kuwait and Saudi Arabia users are currently able to outsource to Edarat their DR. 
Edarat further sponsored Evault at their $9^{\text {th }}$ yearly Datacenter Dynamics Converged in Dubai, The conference was well attended by over 28,000 data center professionals.

\subsection{Policy}

Middle East governments have developed modern suite of laws that strongly facilitate and support cloud computing and the digital economy. Saudi Arabia for example, has in place comprehensive privacy legislation besides intellectual property laws that are relevant to cloud computing. Kuwait and the United Arab Emirates have also developed data protection laws with independent privacy commissioners. The developments are significant to cloud users, owing to confidentiality. The users can now fully accept and adopt the cloud computing with confidence that stored private information stored wherever in the world is likely not to be disclosed by in unexpected ways by the cloud providers. Predictability of National privacy regimes are aimed at transparency and avoidance of unnecessarily burdensome cloud service providers restrictions. Example, being data controller's registration requirements and data transfers across border.

Cloud providers in the Middle East are consequently encouraged by experts to establish effective privacy policies, that can appropriately be used for cloud service and various business models they use. A case in point is the policy intended to gain ministerial approvals. The approval for privately-protected information is only processed or stored in any offshored and outsourced arrangements with pre-approvals. The pre-approvals are only done relevant portfolio ministers and sometimes the minister responsible for overseeing security and privacy that involves government information. Of special concern is, assessment of security risks. Agencies in the Middle East are helped to perform the aforesaid by a cloud security policy that adequately assesses security risks. To ensure the government reduces storage costs and take advantage of cloud computing, Saudi Arabia has initiated external storage and data processing that reside in well-secured and protected domains.

\subsection{Security}

The Middle East governments have a wide initiative that provides security monitoring services and joint authorizations to its citizens based on cloud computing foundation. The IT systems are managed in such a way to ensure comprehensive government-wide risk management. The approach include: integrated vetted approach, and applying federal security requirements consistently. The government allows its agencies to use leverage authorizations, reviewing security details, securing agency usage requirements and leveraging existing authorization. The Authorities dealing with security create requirements that incorporate government-wide baseline to be integrated, developed and approved. The government intelligence coordinate authorization packages provide continuous oversight monitoring and authorize security packages (Chuan, n.d.). Cloud Security Alliance organizations are closely linking with the Middle East governments to make concerted efforts that will use of best practices aimed at providing security assurance within cloud computing

\subsection{Procurement}

To assist the Middle East government agencies and industry capability, commercial services are provided and transacted over an established website application. The purpose of e-procurement is to provide simple and easy ways to research, find, and procure commercial government services and products. Agencies and citizens can search for e-product categories using the software as service application (SaaS), make price quotes, product descriptions and links to more product, and service information. Government procurement is also supported using vehicles such as GSA advantage or GSA Schedule. Information on Apps.Gov are no-cost applications with 'government friendly' agreements of Terms of Service, obtained on social media. Users only have to hit the button SEND REQUEST, and they get a link to a social media coordinator agency who help them complete the request needed to use the tool in compliance with social media policy of the agency. Consequently, cloud based infrastructural service are supported by cloud PMO that works closely with the Federal Acquisition Service. FAS is mandated by the Middle East government to primarily operate on-line acquisition of government-wide use available services and products. Kuwait's Central Agency for Information Technology (CAIT) is pondering the use of cloud computing for storing data at government bodies, linking them in one system, seeking to upgrade the e-government.

\subsection{Military}

The middle east governments such as Kuwait has established a data network that links over 56 governmental bodies, sharing electronic documents and data at a very high speed. The aim of using cloud computing is for easy data recalling and storage. A case of Kuwait cloud computing was established in 2006 and has achieved several projects involving data infrastructure that are needed to develop e-government that incorporates relevant official bodies. There also exist big Data military conferences and exhibitions that includes workshops involving 
renowned worldwide IT specialists, their role is to brief the government and participants from big local companies and official bodies on latest improvements and development $\mathrm{s}$ in cloud computing.

\section{Comparison of Use of Cloud Computing by Other Governments in Providing E-Governance}

Most countries in the Middle East have increasingly acknowledging cloud computing and cloud projects through their various publications and guidance. However, some member states have no or rather very little guidance in e-government and cloud computing. Czech- Republic for example, public authorities have not managed to publish any guidance despite showing interest in cloud computing. The state's interest is reflected in their strategic document that was issued by the Czech Republic entitled Road to Digital Economy. In Finland, the situation is similar with minimal guidance that concerns specifically cloud computing. The Finish authorities have only published questions that relate closely to provision of cloud services, example is outsourcing processing of individual data.

The situation in the United Kingdom is interesting since, there exist no specific cloud computing guideline, but public authorities have been very active in publishing ICO Guidelines that are however only limited to data protection. Poland have a publication famous as the Finance Supervision Commission that was adopted in January 2013. The guideline is however just on specific finance project rather than general cloud computing guidance. The finance Supervision commission helps in environmental security and management of information technology in credit institutions and banks operating in the Polish market (Uden, 2013).

In Germany, The federation for Security and Agency in Information Technology was published in 2012 February. However, there exists no binding guidance document by German industries on cloud computing. The Italian Digital Agency, that is also the Italian public authority regarded as competent for digitalization of the Italian government, provided relating documents that helps in adoption of the cloud computing by Italian public authorities. An example is the features aiming at electronic systems digitalization in the public administration. It captures the possible cloud services that are to be adopted by the public administration, e-government architectural framework, cloud computing role of public administration, "OpenStack" project description as public administration acceptable standards, Public administration data centers cloud services. Interoperability, conformity, security management, requirements of resilience in public administration cloud computing and the classes of services.

Finally, very few countries have provided general guidance that is destined to its citizens and private entities. Examples of such countries include, Belgium. The Federal Public Economy in Belgium has published a cloud computing study that is entitled the "Economic opportunity for Belgium". The strategy offers a standard definition of cloud computing, explores and the legal framework necessary for cloud computing. In France, Similarly, The Information and Network Security Agency that was published in 2010, outsources information systems on cloud computing.

The Agency for Digitalization in Denmark has several papers and guides on cloud computing including that on initiatives of cloud audit assurance, new security models that are digitalized, and cloud legal framework and computing policies. Finally, Spaniards 'public authorities have a National Interoperability Framework that sets out the responsibilities, guidelines and principles in preservation and exchange of electronic information used by the public administration. The circulated guide for cloud security and privacy of companies in 2011 has different cloud computing levels, means of deploying services, and the legal reference frameworks. It is important to look at the main components and implications regarding privacy and security and the keys that will ensure success for usage of cloud computing services.

\subsection{Significance of Cloud Computing to International E-Governance}

E-governance provides a wide opportunity for serving citizens efficiently. ICT has potentially lots of advantages in the governance of any organization with enough efforts of building infrastructure, changing process and capacity enhancement .Increased technology generalization access by organizations and citizens present expectation and government demand. Governments are however very proactive in the cloud computing domain by examining its application, new ways of improving services, interaction and optimizing processes. Cloud computing is likely to prove an ideal solution to the many challenges faced by e-governments from development to implementation. Case studies of e-governance in some international organizations are discussed below:

\subsection{European Union}

The advancement of cloud computing services has advanced communication technologies in the EU. The development of innovative new large-scale business models has enhanced high- speed communications. The EU public authorities have adequately positioned themselves in adopting the new revolution in technology. 
Consequently, cloud computing is well acknowledged by authorities in EU and its member states. The EU framework of digital agenda developed in September 2012 has particularly revealed the great interest in cloud computing. The strategy for unleashing cloud potential in Europe was adopted by the European Commission. The strategy has resulted in adequate analysis of regulatory and overall policy technologies and landscape.

EU has encouraged use of cloud computing across all of its economic sectors. The key actions identified as urgent additional actions include: fair and safe contract conditions and terms, cutting through standards' jungles and establishing a partnership of European cloud. The parliament adopted a resolution following EU Commission of 2012 Strategy, based on the various EU existing instruments and digital agenda in the field of IT. Importantly, it presents the main challenges while examining various issues amongst: cloud as employment and growth instrument, the EU cloud and market, standards, of innovative solutions and public procurement, the cloud and consumer, civil law and intellectual property, law enforcement, fundamental rights and data protection. Finally, the publishing of other recent documents by EU Commission show correlation to cloud computing included is the Staff Working Report in 2014 that presents the cloud computing potential in Europe procurement.

\subsection{NATO}

The partnership by IBM in cloud computing implementation system has helped streamline the data collection by the NATO 28 member international alliance. The United States Federal government has already implemented cloud computing that helps them in military simulation developments, storage and collection of large amounts of data over stipulated time, and IT process stimulation. The private sector however, has implemented cloud computing to assist minimize energy expense, speeding up technological system development and improving their customer service (Rountree \& Castrillo, 2013). NATO's solutions for surveillance, intelligence and reconnaissance among its 28 nations, has been developed by sue of cloud computing.

\section{$6.4 U N$}

The millennium development goals are among cloud computing related endeavors. The aim is to help end extreme poverty by set eight targets worldwide in 2015. The efforts can be achieved through cloud implementation of recommendations by the UN Communication and Information Task Force. Cloud computing in UN is about localizing of e-governance for efficiency globally. Flexible and efficient opportunities, through cloud computing are distributed globally for social and economic stimulus (Talke, Salomo, \& Kock, 2011).

\section{Conclusion}

In more ways than one, cloud computing has really help the Middle East countries not only in governance but in development as a region. Population growth and use of the internet in the Middle East has increased the demand and use of cloud computing making the development of the region raise due to their poise in the reliability and security of the cloud. Governments have already started e-government projects and in the next few years, citizen will have a personalized government portal (www.dubai.ae), Smart-ID card, development of e-government infrastructure, deployment of digital signature and upgrading of government websites with web 2.0 features.

Cloud computing in the Europe and Middle East countries involves the sharing of electronic information/data between organizations, government agencies and departments, the aim being to improve communication, data sharing and data access. They are driven by factors amongst, funding and budgeting of its citizens and the Open Government Directive legislation. Through systems and information sharing, the Middle East and European governments are able to reduce IT costs, streamlining procedures at government offices, citizens are also able to access information using internet. Qualifications for funding and project grants are also fastened. Unlike Middle East cloud computing in Europe has no specific guidelines but their public authorities have been very active in publishing ICO Guidelines that are however only limited to data protection. Unlike Europe, Middle East government agencies, and commercial services are provided and transacted over an established website application. The purpose of e-procurement is to provide simple and easy ways to research, find, and procure commercial government services and products.

\section{Recommendations}

While the adoption of cloud computing in the Middle East is expected to continue rising as people adopt the very latest of technologies, a lack of effective services and reliable vendors is hampering this process, thus something needs to be done with regards to this aspect. Public cloud is yet to be adopted largely because there is a lack of established and reliable vendors.

Another challenge that rocks the region is the shortage of skills in IT. The IT environment in the Middle East is changing rapidly yet the number of the right personnel and talent to deal with the surging numbers is low. Therefore, governments need to invest in the right personnel from their regions. 
The IT sector as a whole also needs investment from everyone and not just the governments. Smalls businesses also need to be involved to ensure that everyone is part and parcel of the process.

\section{References}

Cloud Security Alliance. (2010). Top threats to cloud computing. Retrieved from $\mathrm{http}: / / \mathrm{www} . c l o u d s e c u r i t y a l l i a n c e . o r g / t o p t h r e a t s / c s a t h r e a t s$

Ferrer, M. C. (2009). Zeus in the cloud. Retrieved from http://comunity.ca.com/blogs/securityadvisor/archive/2009/zeus-in-the-cloud.aspx

Firdhous, M., Ghazali, O., \& Hassan, S. (2011). Trust and Trust Management in Cloud Computing-A Survey. Inter Networks Research Group.

Ghaffari, A. R. (2010). Cloud computing systems: Sample, Applications, Challenges. M.Sc. Thesis, Shahid Beheshti University, Tehran.

Gopala, K., Vishnu, V. V., \& Madhusudhana, R. (2009). Service Oriented Architecture for E-Governance.

Gruman, G. (2008). What cloud computing really means. Info World.

Jamil, D., \& Zaki, H. (2011). Security Issues in Cloud Computing and Countermeasures. International Journal of Engineering Science and Technology, 3, 2672-2676.

Keizer, G. (2009). VMware bug allows Windows hack to attack Macs. Computer world. Retrieved from http://www.networkworld.com/news/2009/041509-vmware-bug-allowswindows

KPMG. (2011). The Cloud Changing the Business Ecosystem. Survey report. Retrieved from http://www.kpmg.com/in/en/issueandinsights.com

Krissi, D. (2008). Distinguishing Cloud Computing from Utility Computing.

Kuldeep, V., Shravan, S., \& Amit, R. (2012). A Review of Cloud Computing and E-Governance. International Journal of Advanced Research in Computer Science and Software Engineering, 2(2).

Kyriazis, D., Oberle, K. T., Voith, T., \& Oliveros, E. (2010). A Real-time Service Oriented Infrastructure. International Conference on Real-Time and Embedded Systems (RTES 2010) (Singapore). http://dx.doi.org/10.5176/9789810876548_R47

Layne, K., \& Lee, J. (2001). Developing fully functional e-government: A four Stage model. Government Information Quarterly, 18, 122. http://dx.doi.org/10.1016/S0740-624X(01)00066-1

Monsef, M., \& Gidado, N. (2011). Trust and privacy concern in the Cloud. 2011 European Cup, IT Security for the Next Generation, 1-15.

Proofpoint. (2009). Outbound email and data loss prevention in today's enterprise, 2009. Sunnyvale, C. A: Proofpoint.

Qaisar, S., \& Khawaja, F. K. (2012). Cloud Computing: Network/Security Threats and Countermeasures. Interdisciplinary Journal of Contemporary Research in Business, 3(9), 1323-1329.

Ristenpart, T., Tromer, E., Shacham, H., \& Savaga, S. (2009). Hey, you get off my cloud: Exploring information leakage in third-party compute clouds. In proceedings of the $16^{\text {th }} \mathrm{ACM}$ conference on Computer and communications security, New York, NY: ACM Press.

Sachdeva, K. (2011). Cloud Computing: Security Risk Analysis and Recommendations. Master Thesis, University of Texas, Austin, 2011.

Safari, H., Mohammadian, A., Tamizi, A. R., Farazmand, E., \& Moslehi, A. (2003). Iran's Ministry of Commerce E-GovernmentMaturity Model. Quarterly Journal of Knowledge Management, 63, 53-78.

Sheridan, W. (2006). Electronic Government in Developing and Developed Countries: The Basics. Commonwealth Centre for e-governance, Ottawa, Canada,

Siani, P. (2012). Privacy, Security and Trust in Cloud Computing. HP Laboratories, appeared as a book chapter by Springer, UK.

Soleimanian, F., \& Hashemi, S. (2012). Security Challenges in Cloud Computing with More Emphasis on Trust and Privacy. International Journal of Scientific \& Technology Research, 1(6), 49-54.

Takabi, H., Joshi, J. B. D., \& Ahn, G. (2010). Security and Privacy Challenges in Cloud Computing Environments. IEEE Security Privacy Magazine, 8, 24-33. http://dx.doi.org/10.1109/MSP.2010.186 
Tripathi, A., \& Parihar, B. (2011). E-governance challenges and cloud benefit. VSRD International Journal of CS \& IT, $1(1), 29-35$.

Waseda University International e-Government Ranking. (2013). Retrieved from http://www.waseda.jp/eng/news12/130326_egov.html

Winkler, J. R. (2011). Securing the Cloud: Cloud Computer Security Techniques and Tactics. Elsevier Publishing.

\section{Copyrights}

Copyright for this article is retained by the author(s), with first publication rights granted to the journal.

This is an open-access article distributed under the terms and conditions of the Creative Commons Attribution license (http://creativecommons.org/licenses/by/3.0/). 